\title{
Rule-Based Views and linked building data for efficient planning processes
}

\author{
Christoph Maurer ${ }^{1}$, Anna Wagner ${ }^{2}$, Julian Wengzinek ${ }^{3}$, Uwe Rüppel ${ }^{2}$, Wendelin Sprenger ${ }^{3}$, \\ Tilmann E. Kuhn ${ }^{1}$ \\ ${ }^{1}$ Fraunhofer Institute for Solar Energy Systems ISE, Freiburg, Germany \\ ${ }^{2}$ Institute of Numerical Methods and Informatics in Civil Engineering, TU Darmstadt, Germany \\ ${ }^{3}$ Ed. Züblin AG, Stuttgart, Germany
}

\begin{abstract}
Why are real construction projects still so seldomly assisted by building simulations? Within the research project SolConPro, a new and detailed investigation of the current digitalization processes in construction has been performed. Based on its results, new concepts for data management and for data preprocessing are suggested. By keeping data management independent of the applications, the same data amount can be addressed by several software programs at once. For information management, linked data structures are suggested, while for filtering and preprocessing, a new concept named Rule-Based views (RBV) is suggested. The paper shows the implementation of both innovations by connecting the innovative data management to the BIM software program Autodesk Revit.
\end{abstract}

\section{Introduction}

For this paper, Building Information Modeling (BIM) is defined as the creation, storage, conversion and transmission of digital data to support and increase the efficiency of processes during the entire life-cycle of buildings, from early planning through commissioning and operation to recycling. This definition spans a wide range of software and digital processes and exceeds definitions which limit BIM for example to 3D models of buildings with additional data attached to building components. The wider definition has been chosen because there are no clear boundaries between the creation of $3 \mathrm{D}$ models with additional data, the extraction of the data for building simulations, the creation and storage of results. The efficiency includes many possible benefits, especially improvements in construction time and quality, but also the lower probability of risks in a building project in general. The information transfer from construction requirements to the architect also lowers the amount of required adaptions to the architectural model at a later time. Morever, building simulations can be performed at the time the results are required for decision processes.

First, current BIM processes are analysed regarding barriers which may prevent information flow and the adaption of building simulation software. Second, two conceptional changes are suggested and implemented as a prototype.

\section{Analysis of current BIM processes}

Within the research project SolConPro, a detailed analysis of current digitalization of construction has been performed, leading to the following results.

First, current software programs that allow to create digital twins of constructions tend to restrict the amount of digitalized information to their own environment. For this reason, data required for building simulations has often to be added to the construction description after export. Second, current filtering mechanisms, such as the Model View Definition (MVD) format, are mainly implemented within these software programs and therefore have to be kept simple in structure. Third, most building simulations require geometrical information of the digital construction twin. For data management, however, there is still no format available that completely represents geometrical information independent of software formats. The purpose of the industry foundation classes, IFC, is the data transfer and is therefore, with minor exceptions, restricted to static information. (buildingSMART, 2017)

The main goal of the international organization buildingSMART is the improvement of data transfer processes for the construction industry. For this reason, their suggestions have been analyzed in high technical detail.

Their main development seems to be the Industry Foundation Classes (IFC) mentioned before. The format allows to store the BIM representation of the digital twin, with the focus of storing object-oriented geometrical information including object parameters, independent on software programs. However, with minor exceptions, BuildingSMART has restricted the IFC data to static information, which means that every calculation procedure performed within BIM software programs is lost when the data is exported to IFC. This has the advantage that the geometry kernel procedures of the BIM software programs do not have to be standardized, but it limits IFC to software transfer and documentation purposes. (For this reason, the format is often compared to PDF.)

When more than one software program is applied, the degree of detail of the IFC representation rarely match the requirements of both programs. Therefore, buildingSMART has developed another standard called MVD which can create a subset of the information stored in IFC (buildingSMART, 2019c). Another format 
called Information Delivery Manual (IDM) even defines the process step that requires a certain MVD (buildingSMART, 2019b). IDMs define a certain process step where the MVDs represent the exchange requirements for starting and finishing the activity. The MVDs are mostly implemented within software programs and can be chosen during the IFC export process.

The IDM/MVD approach would be very helpful for industry sectors with sequential processes (like the automotive industry), but this is not the case in construction. Instead, processes are mostly running in parallel and require a high amount of interaction between stakeholders. Decisions often lead to completely changing procedures on construction sites. While process chains can be standardized in other industry sectors, construction processes are dependent on far too many factors for a IDM standardization to be adaptable. For example, the decisions of an architect depend significantly on the decisions of the building owner and of the planners. A process chain which may seem reasonable at one point of time may require adaption soon after because of the strong interaction of the stakeholders.

The analysis of several construction processes lead to the conclusion that the IDM/MVD method has to be replaced by a digitalization approach that matches the special requirements of the construction sector.

Another disadvantage of MVDs is the restriction of the filtering process to the existing data structures. For example, the MVD filtering approach allows to select all walls that contain a certain property. However, it does not allow to select all external walls if the property "external" does not exist. From an IT perspective, it is somehow trivial to implement scripting procedures selecting all external walls; they can be calculated from geometrical information. The MVD approach does not allow such a procedure to be implemented. Another disadvantage of MVDs is the lacking possibility of recalculating geometrical information. Sometimes, software programs require a much higher degree of geometrical information than others. buildingSMART suggests to solve the issue by storing different levels of detail of objects within the BIM software programs. This seems to be a workaround considering the fact that the BIM software program mostly only requires one geometrical representation.

It is also difficult for stakeholders when they need a higher or lower resolution of the data in general. One stakeholder may need the south façade as one element, another needs it in vertical strips with the height of onestorey and a third stakeholders needs façade elements that match the size of the rooms inside. It could therefore be helpful for the stakeholders not to exchange only filters, but also preprocessors for repeating tasks such as the joining and separating of elements.

All the analyzed facts lead to the conclusion that BIM data has to be stored software-independently, connecting different software programs by using powerful filtering and preprocessing routines. This allows performing processes in parallel, which then use and change the same data amount for different purposes. Solving conflicts can then be done by methods like git that are already established in software development, where also several people work on the same data. Then, construction processes do not need to be standardized sequentially anymore, like suggested by IDM.

For the extended filtering and preprocessing methods, the name Rule-Based View (RBV) is suggested. The name is based on the "view" term of the MVD abbreviation, but the part that is filtered to create a certain view on the data amount has been calculated based on rules. One rule would be to reduce the degree of geometrical detail to a certain distance between points. RBVs can be considered as extended MVDs because filtering processes are still part of RBVs. Contrary to MVDs, the filtering and preprocessing routines are performed independent of the applied software programs.

For software programs that offer an Application Programming Interface (API), the import and export processes can be replaced by scripts that directly synchronize the results of RBV operations with the software contents. Within this paper, these scripts are called "wrappers". To combine different rules and wrappers to a final filtering and preprocessing routine, a Graphical User Interface (GUI) has been developed (Figure 1). When available as a GUI, even nonprogrammers can create RBVs. Elements can be selected and connected to a RBV and saved for future re-use.

For example when the use of building-integrated photovoltaics shall be analysed, a planner could get the BIM data as an IFC file and needs to perform a raytracing simulation to determine the irradiance on the building envelope. If the favourite software of the planner is Radiance, she needs the geometry in the the .rad format. But if the entire geometries of the IFC files are converted into the .rad format, the computing time of Radiance exceeds the duration of the building project. Therefore, a RBV is created with the two filters and one wrapper presented by Listing 1 (Eisenlohr et al., 2018). Due to the modularity of the RBV, the modules can be easily reused for other purposes or be improved where necessary.

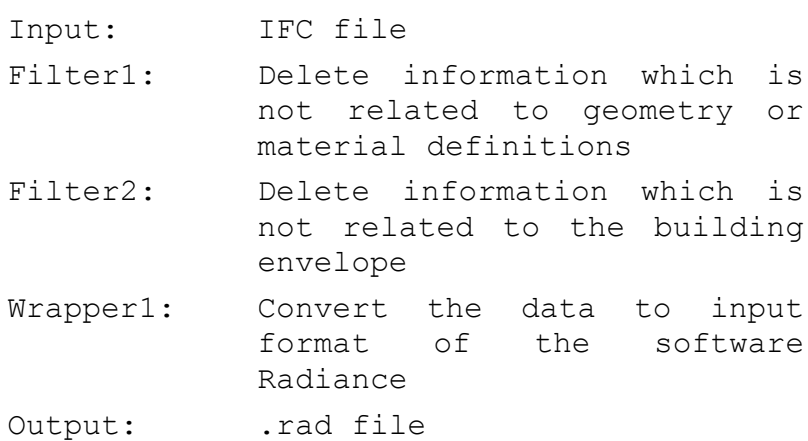

Listing 1 Example of the filters and wrapper of the RBV if $2 \mathrm{rad}$ 
The implementation of RBVs to existing construction processes lead to a more detailed analyses of the IFC standard, where some major disadvantages were identified. First, IFC has a strictly hierarchical schema that is motivated by the dependence of its contents to BIM applications. Hierarchical structures are a major drawback for innovative (or, in general, non-standard) products. Building-integrated photovoltaic façade components are one example. The IFC classification allows to specify building elements as well as distribution elements like photovoltaic elements, but it requires a standardization which entity is used. For example, it is not planned that one element can be at the same time a wall and a photovoltaic element.

While each hierarchy favours some components and disadvantages others, graph-based building data is open for every manufacturer to add an innovative product even if it has not been added to the data schema yet. Every connection in this linked building data can be used for querying and there is no limitation for the number of connections between entities.

Another barrier is that each conventional data scheme like IFC will either have too many or too few entities. Too many for the stakeholders who need just a small subset and are confused by the remaining entities and too few for all stakeholders who want to share or receive data for which there is no entity or which is not allowed to be shared in the suitable format. For example, conventional data schemes do not include yet the option of sharing machine-code functions, although this can be very helpful for example for building simulation (Maurer et al., 2017). In order to keep the data management format flexible for future extensions, the hierarchical structure of IFC has to be replaced by an ontology.

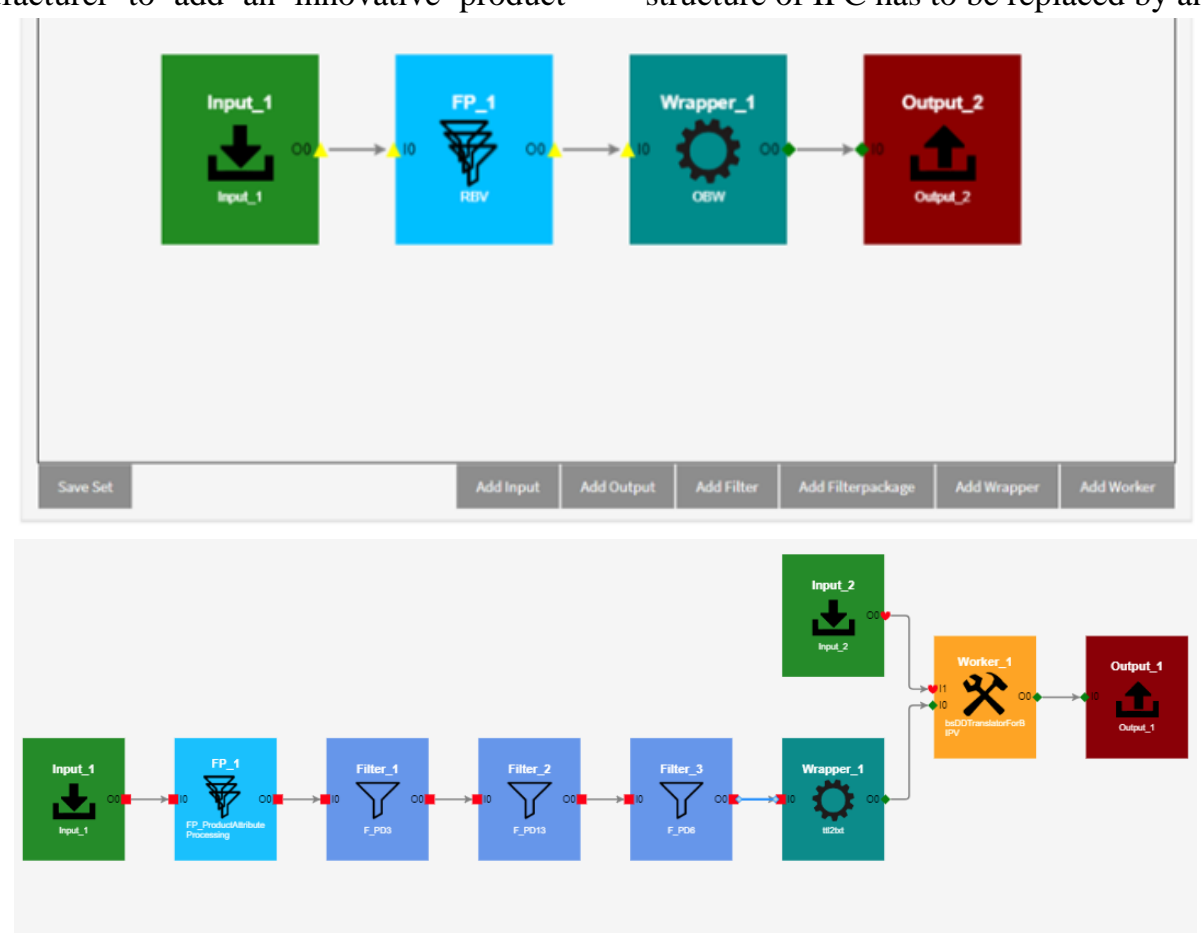

Figure 1: Examples of a GUI to arrange filters, pre-processors and wrappers for RBV.
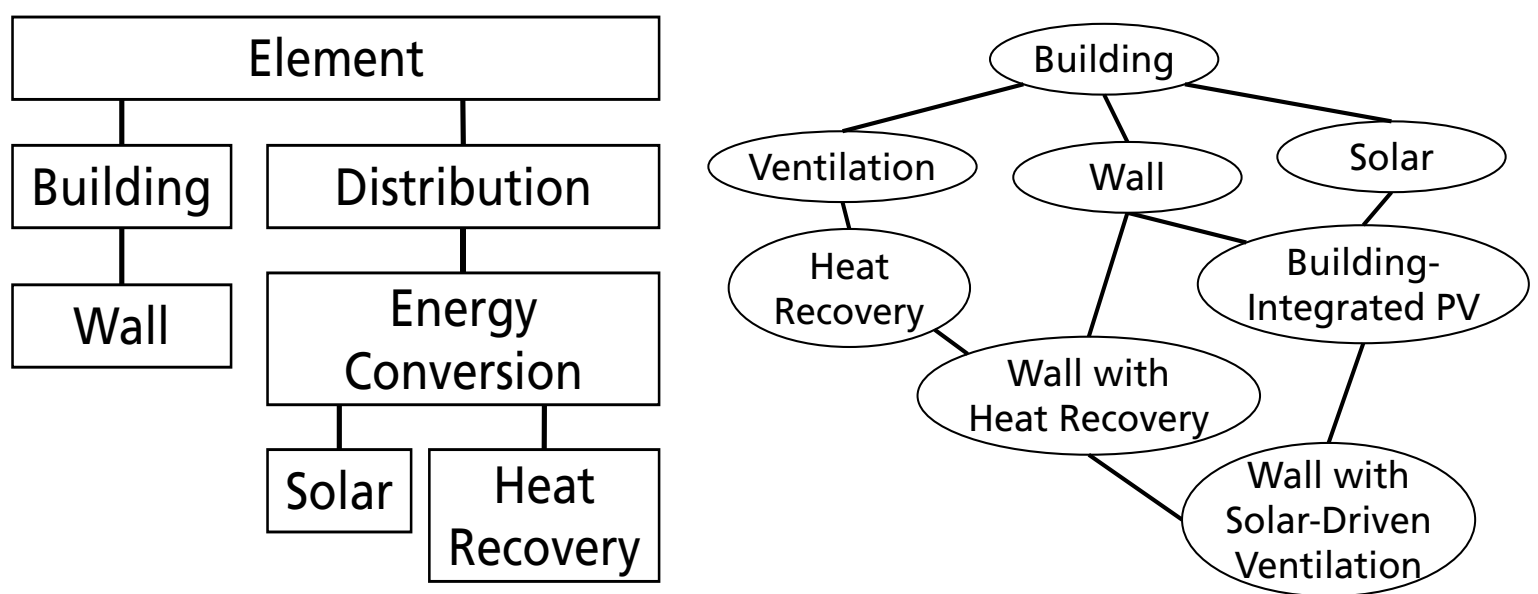

Figure 2: Visualisation of a conventional data scheme (left) and linked building data (right). 


\section{Proposed improvements for future BIM processes}

The improvement of current digitalization activities in the construction industry depends on two milestones. First, the standardization of sequential construction processes has to be replaced by the creation of a software-independent data pool that can be edited simultaneously by different stakeholders. Second, the data structures need to be flexible enough to provide the possibility of arbitrary format extensions. Both milestones can be reached by creating a softwareindependent, graph-based data management system with extended filter and preprocessing routines.

Graph-based data modeling has several advantages (Figure 2). Information can be added without classification restrictions, the format does not have to know in advance which data is stored with it. By implementing RBVs, the amount of stored data can be almost unlimited. Physical properties of construction elements can be added almost arbitrarily without interfering with the limitations of software programs. In this way, all available information can be digitalized, which is not the case in the present digitalization approach.

Another advantage for stakeholders is that with linked data, the possibilities for querying are much more powerful than for conventional data formats. The possibility of finding all necessary data can easily outweigh the initial effort of getting used to the new way of querying.

To create a successful search, the only requirement is to standardize the naming of the involved entities. While buildingSMART tries to standardize naming conventions in construction with the buildingSMART data dictionary (buildingSMART, 2019a), linked data approaches allow to apply different domains where the same term can have different meanings dependent on the stakeholder.

The World Wide Web Consortium (W3C) already provides standards like RDF, OWL and SPARQL in the context of Semantic Web Technologies (SWT) which strongly simplify graph data management and querying procedures (Berners-Lee, Hendler, \& Lassila, 2001; W3C, 2019). The standards allow to establish a data pool distributed over many stakeholders.

Figure 3 presents a schematic drawing of possible workflows with linked building data. Manufacturers use tools to convert their product data into semantic web formats and to offer this product data as a cloud online. A small contractor has for example three projects. The SWT makes is much easier for him to find a fitting product from the provided data of one of the manufacturers. The stakeholders of this building project use tools like RBV to import exactly the data that they need at this moment into their favourite user software. Although the project data should contain all the details that someone may need, the user application is very fast because only the required data is loaded into the application. A versioning and an access control system for the data need to be implemented properly to ensure confidentiality and security. The concept of linked building data for building envelopes was developed in more detail by the authors within the research project SolConPro, including the description of distributed linked product databases (Wagner, Möller, Eller, Leifgen, \& Rüppel, 2018; Wagner, Möller, Leifgen, \& Rüppel, 2018).

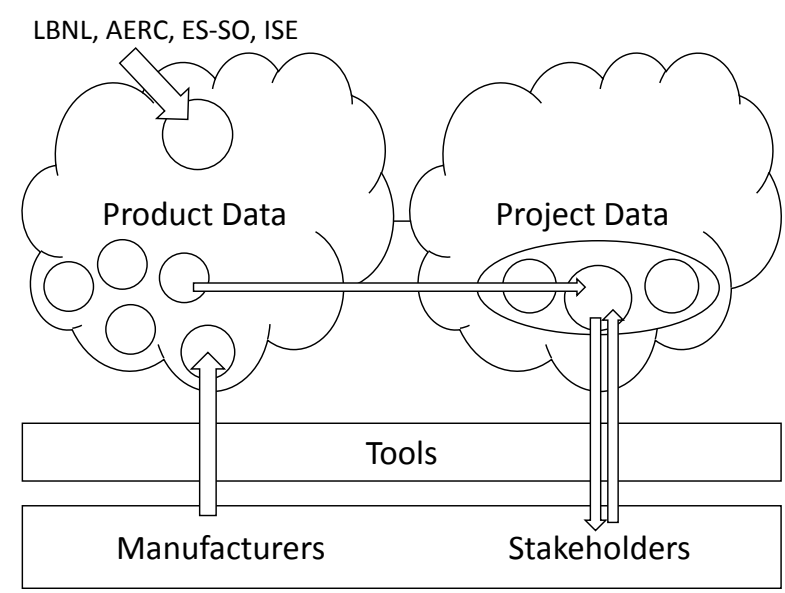

Figure 3: Schematic drawing of example workflows with linked building data.

Lawrence Berkeley National Laboratory (LBNL), Attachment Energy Rating Council (AERC), European Solar Shading Organization (ES-SO) and Fraunhofer Institute for Solar Energy Systems (ISE) have started a project to provide linked building data for windows and complex fenestration systems in a cloud in a way that planners can easily use the data. It will be based on existing databases and software (ES-SDA, 2018; LBNL, 2019).

With a graph-based data pool implemented, arbitrary building simulation software programs can be adapted without any manual step required. Converting data from the data pool to a software-dependent format can be performed in an automated way by applying wrappers.

As soon as enough preprocessing routines and wrappers have been developed, the data synchronization process can be adapted with the help of a Graphical User Interface (as shown in Figure 1), which also allows nonprogrammers to link building simulation programs to the data pool. Furthermore, specific preprocessing tools can be reused for other building simulation programs. Another employee with AEC experience can use the GUI for his building simulations and does not need to understand the preprocessing source code.

\section{Results}

This paper focuses on first implementations of RuleBased Views (RBV) which are described in this section.

First, some elements of building-integrated photovoltaic (BIPV) were modelled with SWT. Figure 4 presents the search for such products. The search provides an overview of suitable products according to Figure 5. The full product data is available for each product (Figure 6). 
Product Search

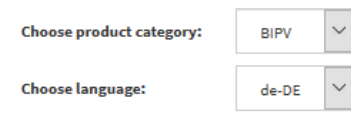

Lengths in $[\mathrm{mm}]$

\begin{tabular}{|l|l|}
\hline AND & OR \\
\hline
\end{tabular}

\begin{tabular}{|c|c|c|c|c|c|c|c|c|}
\hline \multicolumn{2}{|c|}{ Lānge } & $>$ & \multicolumn{3}{|c|}{1000} & $=$ & & $x$ \\
\hline \multicolumn{2}{|c|}{ Breite } & $<$ & , & \multicolumn{2}{|c|}{1000} & 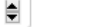 & & $x$ \\
\hline AND & $O R$ & & & & & & + Condition + Constraint & Constraint \\
\hline & Nennleistung & $\checkmark$ & $>$ & $\checkmark$ & 100 & 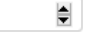 & & $x$ \\
\hline & Preisangabe & $\checkmark$ & $<$ & $v$ & 1500 & $=$ & & $x$ \\
\hline
\end{tabular}

Copyright @ 2015 - 2018 SolConPro. All rights reserved. Impressum.

Figure 4: Screenshot of a search for semantic product data.

\section{Product Search}

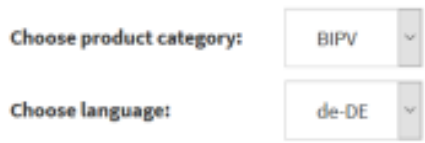

Lengths in $[\mathrm{mm}]$

\begin{tabular}{l|l}
\hline AND & OR \\
\hline
\end{tabular}

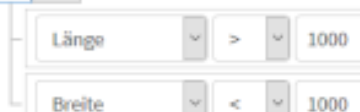

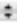

Breite $\quad \psi<\psi 1000$

(1)

Searching for products: Completed $\checkmark$

Processing data: Completed $\checkmark$

5 products found:

\begin{tabular}{|c|c|c|c|c|c|c|}
\hline Produktname & $\begin{array}{l}\text { Länge } \\
\text { [Meter] }\end{array}$ & $\begin{array}{l}\text { Breite } \\
\text { [Meter] }\end{array}$ & $\begin{array}{l}\text { Nennleistung } \\
\text { [Watt] }\end{array}$ & Hersteller & $\begin{array}{l}\text { Preisangabe } \\
\text { [Euro] }\end{array}$ & \\
\hline $\begin{array}{l}\text { Gebäude N, parametrisch, } \\
\text { Zelle } 156\end{array}$ & 1.01 & 0.99 & 125.0 & $\begin{array}{l}\text { Manufacturer } \\
c\end{array}$ & 600 & Choose Product \\
\hline PV shade V2 & 1.524 & 0.974 & 101.2 & $\begin{array}{l}\text { Manufacturer } \\
\text { B }\end{array}$ & 1100 & Choose Product \\
\hline PV Shade V3 & 1.524 & 0.974 & 101.2 & $\begin{array}{l}\text { Manufacturer } \\
\text { A }\end{array}$ & 1000 & Choose Product \\
\hline $\begin{array}{l}\text { Gebäude N, parametrisch, } \\
\text { Zelle } 125\end{array}$ & 1.01 & 0.99 & 133.98 & $\begin{array}{l}\text { Manufacturer } \\
\text { A }\end{array}$ & 500 & Choose Product \\
\hline PV Shade V1 & 1.524 & 0.974 & 101.2 & $\begin{array}{l}\text { Manufacturer } \\
\text { C }\end{array}$ & 950 & Choose Product \\
\hline
\end{tabular}

Copyright 02015 - 2018 SolConPro. All rights reserved. Impressum.

Figure 5: Screenshot of results which match the search criteria. 


\section{Product Details}

Requesting product: Completed $\checkmark$ Processing data: Completed $\checkmark$

Building-integrated photovoltaics module http://vikodb.solconpro.de/GebaeudeN/data/V3

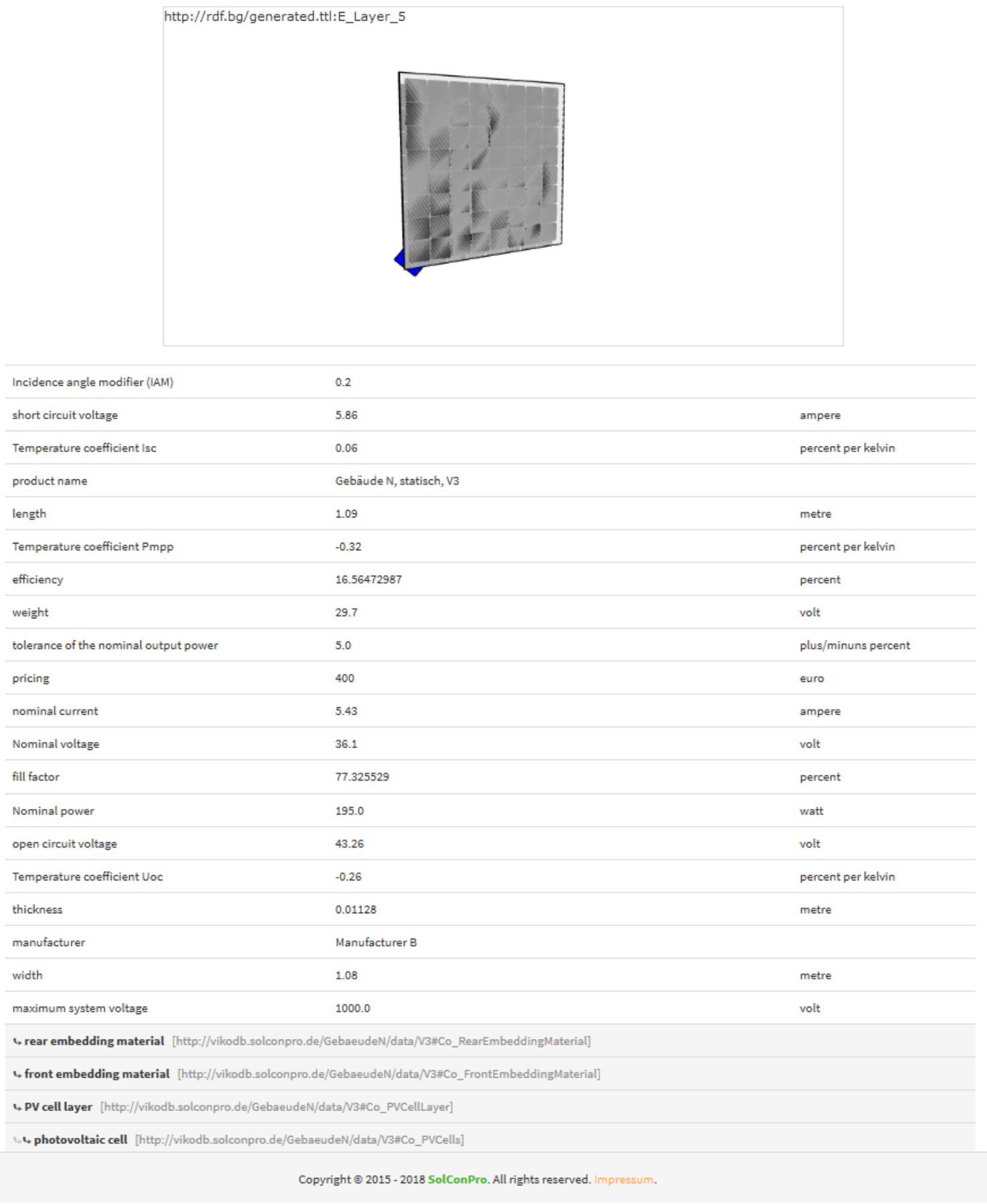

Figure 6: Screenshot of a product data example. 
The next step was the integration of a wrapper into a BIM software. Figure 7 presents how a glazing is highlighted and replaced by a new façade component in a BIM software and Figure 8 shows the new search buttons. In this way, the search for suitable products in the linked building data cloud can be performed according to Figure 9.

The first implementations show that even with limited resources, linked product data can be generated and searched, that RBVs can be created from filters, preprocessors and wrappers in a GUI as presented by Figure 1 and that tools can be established so that stakeholders of a building project can import the linked building data into their favourite proprietary software.

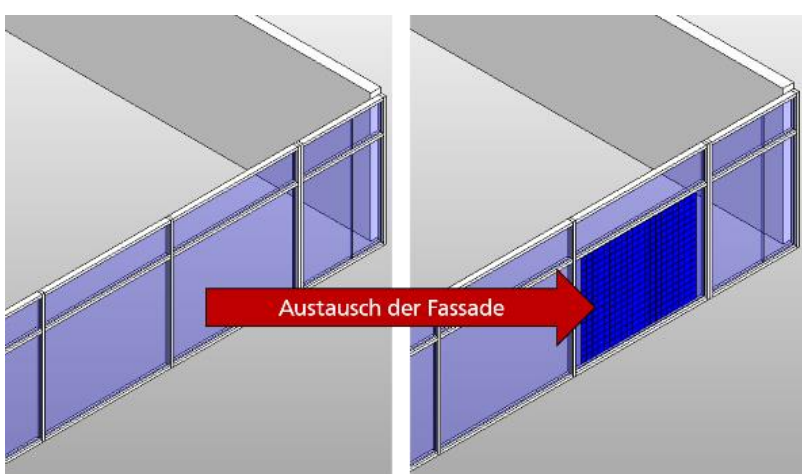

Figure 7: Screenshots of a façade in a BIM software which is highlighted in order to substitute the glazing by another product.

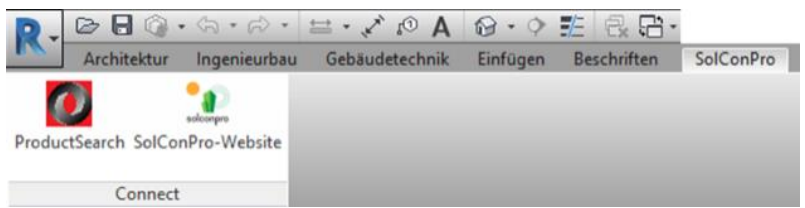

Figure 8: Screenshot of the integration of the semantic product search into a BIM software.

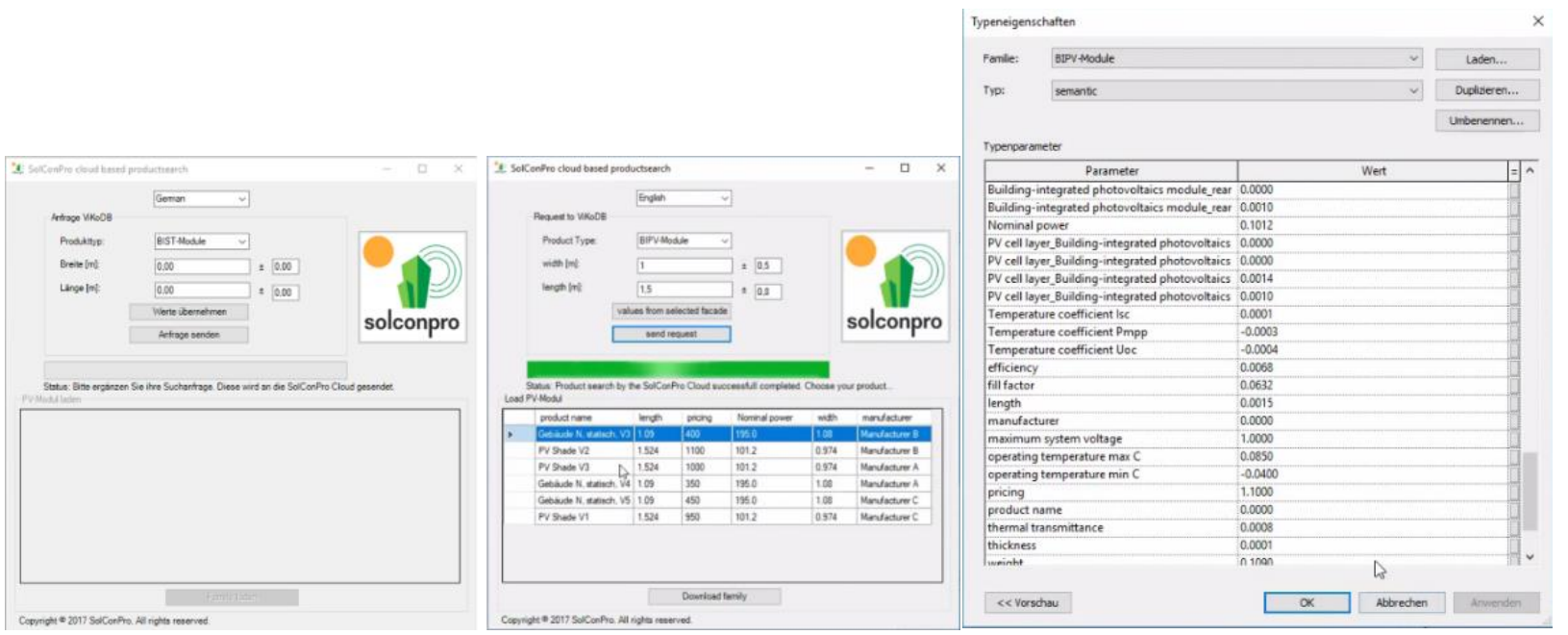

Figure 9: Screenshots of the windows to search for suitable products within the BIM software.

\section{Discussion}

What does the analysis and the proposed improvements mean for building simulation?

First, a common data pool for construction projects means that building simulation tools can be addressed not only at a specific point of time in the planning process but repeatedly. Second, the programming work in research facilities can be performed independent of the choice of BIM software by general contractors and still be applied in practice.

However, not only research facilities and small companies strongly benefit from a software-independent data pool. Also the construction processes of large general contractors become much more efficient, and the information flow between stakeholders improves strongly.

The approach has to deal with one major constraint. Software vendors strongly benefit from incomplete API functions. They force users to restrict their other software programs to those that already provide built-in interfaces with it.

RBVs make building simulation easier because they allow a large amount of project data which contains all necessary information or can at least store all necessary data as soon as it is available. It makes building simulation easier because RBVs can be reused to derive the required input data and to upload the output data of the building simulation. Both effects make building simulation more efficient which may lead to a larger market. Even more important, with powerful filtering and preprocessing tools, the digitalization process gets rid of a very important barrier.

Linked building data does not benefit building simulations directly. It improves the participation of innovative products in the market which may lead to a higher demand of building simulations. Linked building data may contribute to an increased amount of softwareindependent data storage. This could be the basis for more efficient building simulation processes compared 
to BIM data stored in proprietary or incomplete formats which make data access difficult.

As presented by (Mitterhofer, Schneider, Stratbücker, \& Sedlbauer, 2017), SWT can be used to derive a simulation topology to create a simulation model automatically. It is likely that this will not be the last innovative idea with BIM and SWT.

While the implementation of both RBV and linked building data can start to date, it will need time to develop these technologies to a point where they are applied by software products. As the concepts of RBV can already be implemented by filters, preprocessors and wrappers, it can be realized faster than linked building data. Thus, RBVs can be used at present to ease the reuse of old filters, preprocessors and wrappers to extract the necessary input data for building energy modeling and building performance simulation.

The use of linked data in AEC can be continuous for many architects and engineers because they can continue to work with their favourite proprietary software. The wrappers and linked building data stay in the background and support the cooperation with other stakeholders who use their own favourite software. For $\mathrm{RBV}$, the workflows change from one expert who understands the AEC and the programming domain to a cooperation between one expert of the AEC domain and an expert for programming filters, preprocessors and wrappers. Such a cooperation can increase the efficiency of current workflows. It is too early to tell whether the new methods will also lead to new workflows and stakeholders.

\section{Conclusion}

The analysis of current barriers for BIM were used to create two new proposals. The main advantages of rulebased views can be summarized as

- getting rid of a major current barrier of digitalization: the limitation of data amount due to strong dependence on software with restricted data management capabilities

- faster work because software loads only necessary data

- higher quality because of much detailed data is available

The main advantages of linked building data are

- getting rid of another major barrier of digitalization: the difficulty of adding innovative data to existing classification systems

- finding more innovative products

- using the best-suited software instead of the software chosen by another stakeholder

If the power of semantic web technologies is used for rule-based views, many synergies are possible.

\section{Acknowledgements}

This work was funded by the German Federal Ministry for Economic Affairs and Energy (BMWi), based on a decision by the German Bundestag.
The authors thank Lawrence Berkeley National Laboratory (LBNL), Attachment Energy Rating Council (AERC) and European Solar Shading Organization (ESSO) for fruitful discussions and Helen Rose Wilson for fruitful discussions and for proofreading the manuscript.

Both presented innovations, the Rule-Based Views and the adaption of Semantic Web Technologies to construction, and the resulting prototypes are findings of the SolConPro research project. The authors would like to thank all project participants for their efforts and the successful collaboration.

\section{Nomenclature}

$\begin{array}{ll}\text { AEC } & \text { Architecture, Engineering and Construction } \\ \text { API } & \text { Application Programming Interface } \\ \text { BIM } & \text { Building Information Modeling } \\ \text { BIPV } & \text { Building-Integrated Photovoltaic } \\ \text { bSDD } & \text { buildingSMART Data Dictionary } \\ \text { GUI } & \text { Graphical User Interface } \\ \text { IDM } & \text { Information Delivery Manual } \\ \text { IFC } & \text { Industry Foundation Classes } \\ \text { MVD } & \text { Model View Definition } \\ \text { OWL } & \text { Web Ontology Language } \\ \text { RBV } & \text { Rule-Based Views } \\ \text { RDF } & \text { Resource Description Framework }\end{array}$

SPARQL SPARQL Protocol and RDF Query Language SWT Semantic Web Technologies

\section{References}

Berners-Lee, T., Hendler, J., \& Lassila, O. (2001). The Semantic Web. Scientific American, 284(5).

buildingSMART. (2017). Industry Foundation Classes IFC4: Release 4 Add 2 TC1 ISO 16739-1:2018. Retrieved from https://standards.buildingsmart.org/IFC/RELEASE/I FC4/ADD2_TC1/HTML/

buildingSMART. (2019a). buildingSMART Data Dictionary (bSDD) online. Retrieved from http://bsdd.buildingsmart.org/

buildingSMART. (2019b). Website about Information Delivery Manuals (IDM) of buildingSMART. Retrieved from http://idm.buildingsmart.org

buildingSMART. (2019c). Website with the Model View Definition (MVD) of buildingSMART. Retrieved from http://cic.vtt.fi/bSI_LandXML12_MVD/

Eisenlohr, J., Eller, C., Rüppel, U., Leifgen, C., Boudhaim, M., Maurer, C.,... Kuhn, T. E. (2018). Flexible filtering of heterogeneous data using the example of the design and simulation of building integrated photovoltaics. In P. v. Both \& A. Wagner (Eds.), BauSIM2018 - 7. Deutsch-Österreichische IBPSA-Konferenz. 26.-28. September 2018, Karlsruhe, Germany ; Tagungsband (pp.44-50). KIT, Karlsruhe. 
ES-SDA. (2018). Website of the European Solar Shading Database. Retrieved from https://www.esso-database.com/index.php/database

LBNL. (2019). Website of Software provided by LBNL Windows \& Daylighting. Retrieved from https://windows.lbl.gov/software

Maurer, C., Sprenger, W., Franz, S., Boudhaim, M., Lodewijks, J., Rüppel, U., \& Kuhn, T. E. (2017). Machine-code functions in BIM for cost-effective high-quality buildings. Energy and Buildings, 155, 467-474. doi:10.1016/j.enbuild.2017.09.029

Mitterhofer, M., Schneider, G. F., Stratbücker, S., \& Sedlbauer, K. (2017). An FMI-enabled methodology for modular building performance simulation based on Semantic Web Technologies. Building and Environment, 125, 49-59. doi:10.1016/j.buildenv.2017.08.021

W3C. (2019). Website of the World Wide Web Consortium (W3C). Retrieved from https://www.w3.org

Wagner, A., Möller, L. K., Eller, C., Leifgen, C., \& Rüppel, U. (2018). SolConPro: An Approach for the Holistic Integration of Multi-Functional Façade Components into Buildings' Lifecycles. In K. Mela, S. Pajunen, \& V. Raasakka (Eds.), 17th International Conference on Computing in Civil and Building Engineering Conference Proceedings (pp. 951-958). Tampere, Finnland. Retrieved from http://tubiblio.ulb.tu-darmstadt.de/105498/

Wagner, A., Möller, L. K., Leifgen, C., \& Rüppel, U. (2018). SolConPro: Describing multi-functional building products using semantic web technologies. In J. Karlshøj \& R. J. Scherer (Eds.): 12, EWork and eBusiness in architecture, engineering and construction: proceedings of the 12th European Conference on Product and Process Modelling (ECPPM 2018) (pp. 447-455). CRC Press. Retrieved from http://tubiblio.ulb.tu-darmstadt.de/108256/ 